\title{
In Vivo Assessment of Neural Precursor Cell Cycle Kinetics in the Amphibian Retina
}

\author{
Morgane Locker ${ }^{1,2}$ and Muriel Perron ${ }^{1,2}$ \\ ${ }^{1}$ Paris-Saclay Institute of Neuroscience, CERTO-Retina France, CNRS, Univ Paris-Sud, University Paris-Saclay, \\ 91405 Orsay, France
}

\begin{abstract}
Cell cycle progression is intimately linked to cell fate commitment during development. In addition, adult stem cells show specific proliferative behaviors compared to progenitors. Exploring cell cycle dynamics and regulation is therefore of utmost importance, but constitutes a great challenge in vivo. Here we provide a protocol for evaluating in vivo the length of all cell cycle phases of neural stem and progenitor cells in the post-embryonic Xenopus retina. These cells are localized in the ciliary marginal zone (CMZ), a peripheral region of the retina that sustains continuous neurogenesis throughout the animal's life. The CMZ bears two tremendous advantages for cell cycle kinetics analyses. First, this region, where proliferative cells are sequestered, can be easily delineated. Second, the spatial organization of the CMZ mirrors the temporal sequence of retinal development, allowing for topological distinction between retinal stem cells (residing in the most peripheral margin), and amplifying progenitors (located more centrally). We describe herein how to determine CMZ cell cycle parameters using a combination of (i) a cumulative labeling assay, (ii) the percentage of labeled mitosis calculation, and (iii) the mitotic index measurement. Taken together, these techniques allow us to estimate total cell cycle length $\left(\mathrm{T}_{\mathrm{C}}\right)$ as well as the duration of all cell cycle phases $\left(\mathrm{T}_{\mathrm{S} / \mathrm{G} 2 / \mathrm{M} / \mathrm{G} 1}\right)$. Although the method presented here was adapted to the particular system of the CMZ, it should be applicable to other tissues and developmental stages as well.
\end{abstract}

MATERIALS

It is essential that you consult the appropriate Material Safety Data Sheets and your institution's Environmental Health and Safety Office for proper handling of equipment and hazardous materials used in this protocol.

RECIPES: Please see the end of this protocol for recipes indicated by $<R>$. Additional recipes can be found online at http://cshprotocols.cshlp.org/site/recipes.

\section{Reagents}

\section{1-butanol (100\%)}

5-ethynyl-2'-deoxyuridine (EdU) (Thermo Fisher Scientific)

Alexa-coupled secondary antibody $(1 \mathrm{mg} / \mathrm{mL})$ (e.g., Thermo Fischer Scientific)

Antifade mounting medium (e.g., FluorSave reagent [Thermo Fischer Scientific])

Anti-phospho-Histone H3 (PH3) antibody (1 mg/mL) (e.g., Millipore 06-570)

\footnotetext{
${ }^{2}$ Correspondence: morgane.locker@u-psud.fr; muriel.perron@u-psud.fr

From the Xenopus collection, edited by Hazel L. Sive.

Supplemental material is available for this article at cshprotocols.cshlp.org.

(C) 2019 Cold Spring Harbor Laboratory Press

Cite this protocol as Cold Spring Harb Protoc; doi:10.1101/pdb.prot105536
} 
M. Locker and M. Perron

Blocking solution (PBT with 10\% goat serum)

Click-iT EdU Alexa Fluor imaging kit (Thermo Fisher Scientific)

Follow the manufacturer's instructions for preparing stock solutions.

Ethanol (100\%)

Prepare $95 \%, 70 \%$, and $50 \%$ solutions in $1 \times$ PBS.

Glycerin albumen (100\% stock solution) (e.g., VWR)

Store stock solution at $-20^{\circ} \mathrm{C}$. Immediately before use, prepare a fresh $3 \%$ solution in $\mathrm{dH}_{2} \mathrm{O}$.

$\mathrm{HCl}(2 \mathrm{~N})$ (optional, if using bromo-2'-deoxyuridine [BrdU] instead of EdU)

Hoechst 33342 fluorescent stain $(5 \mu \mathrm{M})$

Modified Barth's saline (MBS) $<\mathrm{R}>$

Paraffin wax (e.g., 00403 HISTOWAX [Histolab])

Paraformaldehyde (PFA) (4\%)

PBT (1× PBS, $0.2 \%$ Triton X-100)

Phosphate-buffered saline (PBS) (1×, pH 7.2-7.6)

Tricaine methanesulfonate solution (MS222) (Sigma-Aldrich) (0.4 g/L buffered to $\mathrm{pH} 7.0-7.5$ with sodium bicarbonate)

Unmasking citrate solution ( $10 \mathrm{~mm}$ sodium citrate, $0.05 \%$ Tween 20 in $\mathrm{dH}_{2} \mathrm{O}$ )

Xylene (100\%)

\section{Equipment}

Coplin jars (glass)

Embedding molds (plastic, disposable)

Fluorescence microscope

Heating plate at $50^{\circ} \mathrm{C}$

Humidified chamber

Image processing software (e.g., FIJI or Adobe Photoshop)

Incubators at $18^{\circ} \mathrm{C}-20^{\circ} \mathrm{C}, 37^{\circ} \mathrm{C}$, and $60^{\circ} \mathrm{C}$

Microscope slides and coverslips

Microtome (e.g., Microm HM 340E)

Parafilm or GelBond (Lonza)

Petri dishes

Pipettes (plastic)

Razor blades

Roller shaker

Vials (glass)

For the principles of the methods described here for determining the total cell cycle length $\left(T_{C}\right)$ and the duration of the cell cycle phases $\left(T_{S / G 2 / M / G 1}\right)$, see Box 1 . Note that if determination of all cell cycle parameters is required, it is preferable to deduce them from a unique combined experiment on sibling tadpoles.

Labeling Tadpoles with EdU

1. Raise tadpoles in $0.1 \times \mathrm{MBS}$ in Petri dishes in an incubator at $18^{\circ} \mathrm{C}-20^{\circ} \mathrm{C}$ until stage $41-42$.

2. Transfer the tadpoles to $0.1 \times$ MBS containing $1 \mathrm{~mm}$ EdU.

If analysis is to be performed at embryonic stages (i.e., before or until stage 39/40), microinjection into the yolk is preferable to bathing, since it produces more homogeneous labeling. After microinjection, bathing in EdU solution is sufficient. 
3. Incubate the tadpoles for the desired duration of EdU exposure.

Typical time periods are indicated in Figure 1A. For long exposure times, the medium should be renewed every other day so that EdU remains constantly available.

\section{BOX 1. PRINCIPLES OF THE METHODS}

\section{Principle of $T_{C}$ and $T_{S}$ Determination through Cumulative EdU Labeling}

Total cell cycle length $\left(\mathrm{T}_{\mathrm{C}}\right)$ and $\mathrm{S}$-phase length $\left(\mathrm{T}_{\mathrm{S}}\right)$ can be determined using cumulative labeling with thymidine analogs such as bromo-2'-deoxyuridine (BrdU) or 5-ethynyl-2'-deoxyuridine (EdU). Theoretically, this method presupposes that all cells studied are proliferating (or that nonproliferative cells can be distinguished and excluded) and uniformly distributed in the cell cycle, and that the population grows at a steady state (Nowakowski et al. 1989). The principle relies on the sequential administration of the chosen thymidine analog for a time that exceeds the presumed cell cycle length. The longer the pulse is, the more cells will go through S-phase and be labeled, until all proliferative cells are labeled (Fig. 1A,B). When determined for each pulse duration and plotted as a function of time, the proportion of labeled cells (also called the labeling index [LI]) increases linearly until a plateau is reached (Fig. 1C). The LI at the plateau allows estimation of the proportion of proliferative cells in the considered population (or growth fraction [GF]). As depicted in Figure $1 \mathrm{~A}$, the time needed to reach the plateau $\left(T_{\text {plateau }}\right)$ is equivalent to $T_{C}-T_{S}$. $A$ second equation derives from the fact that in a population of asynchronous cycling cells, the fraction of cells in a given phase is directly proportional to the length of that phase relative to total cell cycle length (Nowakowski et al. 1989). Thus, $T_{S} / T_{C}$ can be deduced from the proportion of $S$-phase cells among proliferative cells at $T_{0}$, which corresponds to the $\mathrm{LI}$ at $\mathrm{T}_{0}\left(\mathrm{LI}_{0}\right.$; extrapolated from the intercept of the best-fit line with the $y$-axis) corrected by the growth fraction. It is therefore equal to $\mathrm{LI}_{\mathrm{O}} / \mathrm{GF}$. $\mathrm{T}_{\mathrm{C}}$ and $\mathrm{T}_{\mathrm{S}}$ can then be calculated from these two equations:

$$
\begin{gathered}
\mathrm{T}_{\mathrm{C}}-\mathrm{T}_{\mathrm{S}}=\mathrm{T}_{\text {plateau }}, \\
\mathrm{T}_{\mathrm{S}} / \mathrm{T}_{\mathrm{C}}=\mathrm{LI}_{0} / \mathrm{GF} .
\end{gathered}
$$

\section{Principle of $T_{G 2}$ Determination Using the PLM Method}

$\mathrm{T}_{\mathrm{G} 2}$ determination relies on a paradigm called the percentage of labeled mitosis (PLM) (Quastler and Sherman 1959). Here again, the idea is to expose the tissue of interest to a thymidine analog, such as EdU, with increasing exposure times. One should then focus on the appearance of EdU-labeled cells among mitotic cells (immunostained with the late G2/M-phase marker phospho-Histone $\mathrm{H} 3$ or PH3 [Hendzel et al. 1997]). These represent the cells that were in S-phase and then went through G2 to finally reach M-phase during the EdU pulse (Fig. 1D,E). PLM increases sigmoidally as a function of time until all cells are double-labeled. Importantly, the duration of the EdU pulse required to reach the plateau is here much lower than in the cumulative labeling experiment. As depicted in Figure 1D, it grossly corresponds to $\mathrm{T}_{\mathrm{G} 2}+$ $\mathrm{T}_{\mathrm{M}}$. After plotting the results (Fig. 1F), the time required for half-maximal appearance of EdU labeling in the mitotic population is taken as an estimation of the average $\mathrm{T}_{\mathrm{G} 2}$ (Arai et al. 2011).

\section{Principle of $T_{M}$ Determination Using the Mitotic Index}

$M$ phase length determination relies again on the fact that the proportion of cells in a given phase is proportional to the ratio between the corresponding phase length and total cell cycle duration. Thus, with the mitotic index (MI) representing the percentage of mitotic cells in a given population, we can deduce the following equation:

$$
\mathrm{T}_{\mathrm{M}} / \mathrm{T}_{\mathrm{C}}=\mathrm{MI} / \mathrm{GF}
$$

Evaluation of the mitotic index represents an easy way to qualitatively compare $T_{C}$ in different experimental conditions under the hypothesis that $M$-phase duration is constant. If $\mathrm{T}_{\mathrm{C}}$ and $\mathrm{GF}$ have been determined through EdU cumulative labeling, then $T_{M}$ can be calculated. 
A
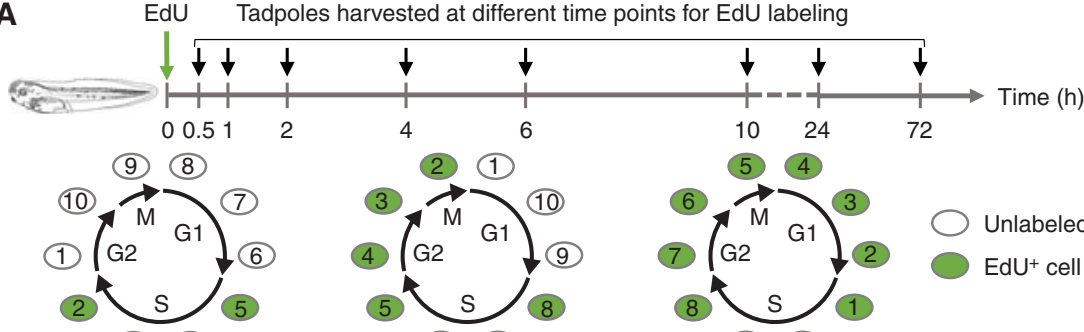

(3) 4

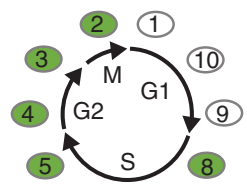

(6) 7

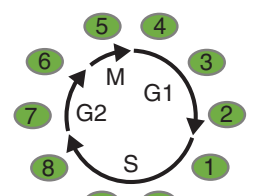

Unlabeled cell

$\mathrm{EdU}^{+}$cell

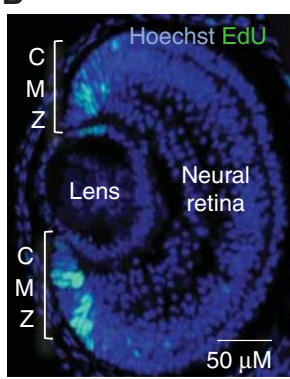

Tc-Ts

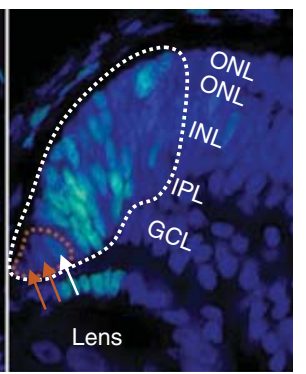

C

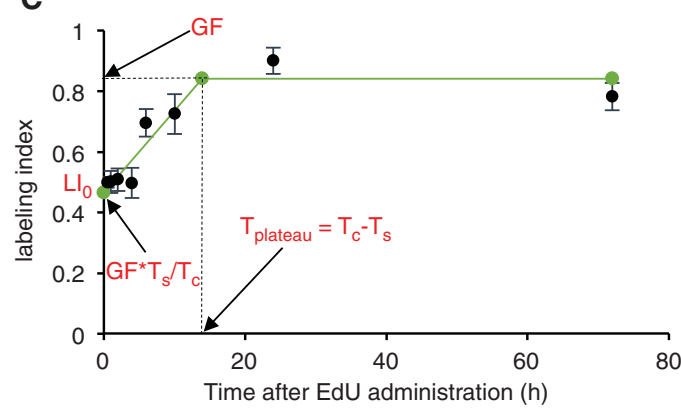

D EdU Tadpoles harvested at different time points for EdU and $\mathrm{PH} 3$ labeling

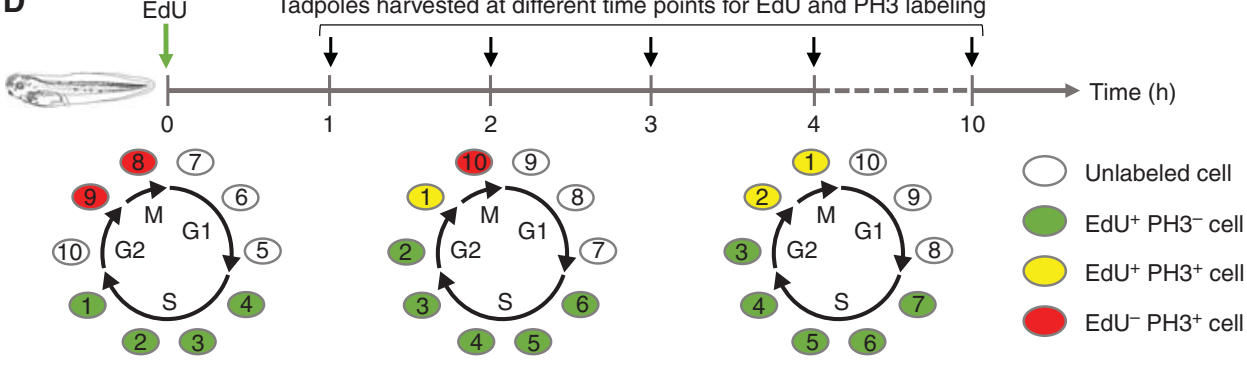

$\mathrm{T}_{\mathrm{G} 2}+\mathrm{T}_{\mathrm{M}}$

$E$

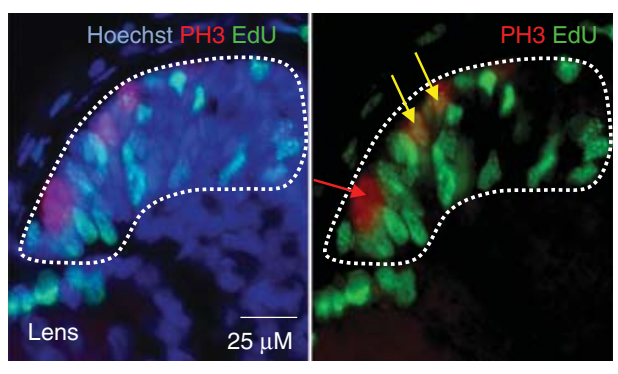

$\mathbf{F}$

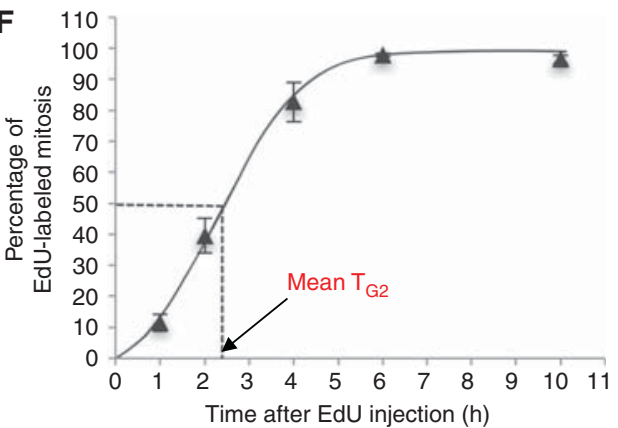

FIGURE 1. Determination of $\mathrm{T}_{\mathrm{C}}$ and $\mathrm{T}_{\mathrm{S}}$ from a cumulative $\mathrm{EdU}$ labeling experiment and calculation of $\mathrm{T}_{\mathrm{G} 2}$ using the percentage of labeled mitosis (PLM) paradigm. (A) Outline of the experiment and schematic representation of cumulative labeling during cell cycle progression. Tadpoles are exposed to EdU for different durations and then fixed, sectioned and subjected to EdU labeling. Ten cells (numbered 1 to 10) are represented on the schematic. Cells become labeled (green) when they reach S-phase. Thus, the longer the EdU pulse is, the higher is the number of EdU-positive cells. As shown on the schematic, the time needed for all cells to be labeled corresponds to $T_{C}-T_{S}$ (follow, for instance, cell number 1). For simplification, the doubling of cells after mitosis is not represented. (B) Typical retinal section stained for EdU following a 4-h pulse at stage 41. Nuclei are counterstained with Hoechst. The panel on the right is a higher magnification of the dorsal CMZ. Red and white arrows point to $\mathrm{EdU}^{-}$and $\mathrm{EdU}^{+}$cells, respectively. Quantification can be performed in the stem cell compartment (delineated in orange and corresponding to the 3-5 most peripheral cells), in progenitors only, or in the whole CMZ (delineated in white using the plexiform layers as frontiers with the differentiated neural retina). (Legend continues on following page.) 
Fixing, Dehydrating, and Sectioning Tadpoles

Here we describe microtome sectioning of tadpoles; alternatively, cryostat sectioning can be performed.

4. Anesthetize the tadpoles in $0.4 \mathrm{~g} / \mathrm{L}$ MS222. Transfer them to glass vials using plastic pipettes.

5. Fix the tadpoles in $4 \%$ PFA with gentle agitation on a roller shaker for $2 \mathrm{~h}$ at room temperature or overnight at $4^{\circ} \mathrm{C}$.

6. Wash the tadpoles three times for 5 min per wash in $1 \times$ PBS.

7. Dehydrate the tadpoles as follows.

i. Incubate three times for $30 \mathrm{~min}$ in $70 \%$ ethanol.

ii. Incubate once for $30 \mathrm{~min}$ in $95 \%$ ethanol.

iii. Incubate three times for $1 \mathrm{~h}$ in $100 \%$ ethanol.

Tadpoles can be stored in $100 \%$ ethanol at $-20^{\circ} \mathrm{C}$.

iv. Incubate overnight in 100\% 1-butanol at room temperature.

8. Transfer the tadpoles to embedding molds. Remove the excess butanol and replace it with melted paraffin wax.

9. Incubate the tadpoles for $\sim 6 \mathrm{~h}$ at $60^{\circ} \mathrm{C}$. Change the paraffin wax $3-4$ times during this incubation.

10. Align the tadpoles in each mold and let the paraffin solidify at room temperature.

11. Remove a paraffin block from the mold and cut around the tadpole with a razor blade. Place the embedded tadpole on a microtome (ventral side down, anterior in your direction). Trim at $50 \mu \mathrm{M}$ to remove excess paraffin, and then section the tadpole at 10-12 $\mu \mathrm{M}$.

12. Arrange successive ribbons containing eye sections on annotated slides covered with $3 \%$ glycerin albumen. Place the slides on a heating plate at $50^{\circ} \mathrm{C}$. Wait for $20-30 \mathrm{sec}$ and then remove the excess liquid. Allow the slides to dry for $10 \mathrm{sec}$ on the heating plate.

13. Transfer the slides to a rack and incubate overnight at $37^{\circ} \mathrm{C}$ to dry.

After this step, slides can be stored at room temperature in a dry place.

FIGURE 1. (Continued) (CMZ) ciliary marginal zone, (GCL) ganglion cell layer, (INL/ONL) inner/outer nuclear layer, (IPL/OPL) inner/outer plexiform layers. $(C)$ When labeling index ( $\mathrm{LI}$ ) is plotted as a function of time, a linear increase is observed until a plateau is reached. This allows determination of the proportion of cycling cells, or growth fraction (GF). The intercept of the linear part of the curve with the $y$-axis $\left(\mathrm{LI}_{0}\right)$ corresponds to $\mathrm{GF} \times \mathrm{T}_{\mathrm{S}} / \mathrm{T}_{\mathrm{C}}$. The time taken for $\mathrm{LI}$ to reach the plateau ( $T_{\text {plateau }}$ ) corresponds to $T_{C}-T_{S}$. The graph shown here is related to an EdU cumulative labeling experiment analyzed in the stem cell compartment and was adapted from Cabochette et al. (2015). (D) Outline of the experiment and schematic representation of $\mathrm{PH} 3$ and $\mathrm{EdU}$ labeling along with cell cycle progression. Tadpoles are exposed to EdU for different durations and then fixed, sectioned and subjected to double EdU/PH3 labeling. Ten cells (numbered 1 to 10) are represented on the schematic. During the EdU pulse, only cells that go through S-phase are EdU-labeled (green). This cohort then progresses through the cell cycle. If the duration of the EdU pulse is less than the G2-phase length, there will be no EdU-labeled cells among PH3-positive cells (red). When the duration increases, EdU-labeled cells appear among mitotic cells (yellow), as they had enough time to go through $\mathrm{S}$ and reach late G2/M phase. The minimal time required to obtain 100\% double-labeled cells corresponds to the sum of G2- and M-phase lengths (follow, for instance, cell number 1 ). For simplification, the doubling of cells after mitosis is not represented. $(E)$ Typical retinal sections (zoom on the dorsal $\mathrm{CMZ}$; delineated in white) stained for both $\mathrm{PH} 3$ and EdU following a 2-h pulse at stage 41 . Nuclei are counterstained with Hoechst. Red and yellow arrows point to $\mathrm{PH} 3^{+}-\mathrm{EdU}^{-}$and $\mathrm{PH}^{+}-$ $\mathrm{EdU}^{+}$cells, respectively. Note that the shortness of the M-phase and thus the weak probability of finding mitotic cells in the stem cell compartment complicates the calculation of their G2-phase duration with this method. $(F)$ Percentage of EdU-positive cells among mitotic cells plotted as a function of time. The time required for half-maximal appearance of $\mathrm{EdU}$ labeling in the mitotic population is taken as an estimation of the mean $\mathrm{T}_{\mathrm{G} 2}$. The graph shown here is related to an experiment analyzed in the whole CMZ and was adapted from Cabochette et al. (2015). 
M. Locker and M. Perron

\section{Rehydrating Sections, Unmasking Epitopes, and Saturating Unspecific Fixation Sites}

Citrate unmasking (Step 17) is necessary for PH3 detection on paraffin sections, but can be skipped if using cryostat sections or if performing EdU labeling only.

14. Transfer the slides to glass Coplin jars. Bathe twice for $10 \mathrm{~min}$ in $100 \%$ xylene to remove the paraffin wax.

15. Rehydrate the sections for 5 min per solution in $100 \%, 95 \%, 70 \%$, and $50 \%$ ethanol.

16. Wash the slides three times for $5 \mathrm{~min}$ per wash in $1 \times$ PBS.

17. Microwave the slides in the unmasking citrate solution: Use maximal power (around $900 \mathrm{~W}$ ) until boiling, and then use the defrost program (around $300 \mathrm{~W}$ ) for $10 \mathrm{~min}$. Cool the slides for 20 min at room temperature.

18. Wash the slides twice in $\mathrm{dH}_{2} \mathrm{O}$ followed by three times in $1 \times \mathrm{PBS}$ for $5 \mathrm{~min}$ per wash.

If using BrdU instead of EdU, add a denaturation step (45 min treatment in $2 \mathrm{~N} \mathrm{HCl} \mathrm{followed} \mathrm{by} \mathrm{three} \mathrm{washes}$ in $1 \times$ PBS for 5 min per wash) before proceeding to permeabilization (Step 19).

19. Permeabilize the tissues for $20 \mathrm{~min}$ in PBT.

20. Transfer the slides to a horizontal surface in a humidified chamber. (Do not allow them to dry.) Add $800 \mu \mathrm{L}$ per slide of blocking solution. Incubate for $20 \mathrm{~min}$ at room temperature.

\section{Staining EdU-Labeled Cells}

EdU staining relies on a copper-catalyzed covalent reaction between the fluorescent dye azide and the EdU alkyne (the "Click-iT" reaction). In contrast to BrdU detection, no DNA denaturation is required, since the small size of the dye azide allows it to easily gain access to DNA. Of note, EdU staining can be followed by immunofluorescence against a marker of interest in order to specifically label a given cell population. However, depending on the antibody used (e.g., anti-GFP[green fluorescent protein]), immunolabeling should be performed before the Click-iT reaction.

21. Discard the blocking solution from the slides and replace it with $200 \mu \mathrm{L}$ per slide of the Click-iT reaction cocktail prepared according to the manufacturer's instructions.

22. Cover the slides with Parafilm or GelBond. Incubate for $30 \mathrm{~min}$ in a humidified chamber at room temperature in the dark.

23. Transfer the slides to glass Coplin jars and wash three times for 5 min per wash in PBT. (Allow the Parafilm or GelBond to detach by itself and then remove it.)

If performing both $\mathrm{EdU}$ and $\mathrm{PH} 3$ labeling, proceed to Step 24. If performing only EdU staining, proceed directly to Step 31.

Labeling PH3 and Counterstaining Nuclei

24. Repeat blocking as described in Step 20.

25. Discard the blocking solution from the slides and replace it with $200 \mu \mathrm{L}$ per slide of primary antibody solution (anti-PH3 diluted 1:500 in blocking solution).

If using BrdU as a thymidine analog, perform a double immunostaining against both $\mathrm{PH} 3$ and BrdU.

26. Cover the slides with Parafilm or GelBond. Incubate in a humidified chamber overnight at $4^{\circ} \mathrm{C}$ or for $2 \mathrm{~h}$ at room temperature.

27. Transfer the slides to glass Coplin jars and wash three times for 5 min per wash in $1 \times$ PBS. (Allow the Parafilm or GelBond to detach by itself and then remove it.)

28. Transfer the slides to a horizontal surface and add $400 \mu \mathrm{L}$ per slide of ALEXA-coupled secondary antibody (diluted 1:1000 in blocking solution).

29. Incubate the slides for $2 \mathrm{~h}$ in a humidified chamber at room temperature in the dark.

30. Transfer the slides to glass Coplin jars and wash three times for 5 min per wash in $1 \times$ PBS. 
31. Incubate the slides for $10 \mathrm{~min}$ in Hoechst solution to counterstain the nuclei.

32. Wash the slides twice for 5 min per wash in $1 \times$ PBS.

33. Transfer the slides to a horizontal surface and apply a few drops of FluorSave reagent (or an equivalent antifade mounting medium) to each slide. Place coverslips carefully on top of the mounting medium.

34. Allow the slides to dry overnight at $4^{\circ} \mathrm{C}$.

35. Proceed to imaging using a fluorescence microscope.

\section{Counting Manually in the Ciliary Marginal Zone}

Automatized counting using appropriate software such as FIJl is difficult in the ciliary marginal zone (CMZ). Because of the high nucleo-cytoplasmic ratio, nuclei appear packed together, rendering their automatic identification challenging. Manual counting must thus be performed, which probably represents the most arduous part of the described experiment. For each experimental condition, we recommend analyzing 6-10 sections (transverse sections that pass through the lens) per retina on 3-5 different retinas. This is usually enough for cell cycle kinetics experiments in the whole CMZ. If restricting the analysis to the stem cell compartment, anticipate needing a larger number of tadpoles to ensure a sufficient number of counted cells and reliable results.

36. Open the images using FIJI or Adobe Photoshop.

37. On each section, delineate the dorsal and ventral CMZ using the outer and inner plexiform layers as frontiers to separate CMZ cells from neuronal layers (Fig. 1B).

38. For all considered retinas, count on each $\mathrm{CMZ}$ section the number of $\mathrm{PH} 3$-positive cells, the number of EdU-labeled cells and the number of PH3-positive cells colabeled with EdU. Count the number of Hoechst-positive nuclei to estimate the total number of cells considered.

39. Report the results in an Excel spreadsheet. For each retina at each desired time point, calculate the percentage of (i) PH3-positive cells among total counted cells, (ii) EdU-labeled cells among total counted cells, and (iii) EdU-positive cells among total counted mitotic cells. Then, calculate mean percentages per retina and standard deviations for all these parameters.

40. If comparing different experimental conditions (e.g., gain or loss of function of your favorite gene vs. control), proceed to statistical analysis for each time point using the nonparametric MannWhitney test.

\section{Calculating Cell Cycle Parameters}

An explanation of the calculations is provided in Box 1.

\section{Calculating $T_{C}$ and $T_{S}$}

41. Plot the average percentage of EdU-positive cells as a function of time (Fig. 1C).

42. Determine the growth fraction (GF) which corresponds to the percentage of labeled cells at the time at which the plateau is reached $\left(\mathrm{T}_{\text {plateau }}\right)$.

43. Determine the labeling index $\left(\mathrm{LI}_{0}\right)$ at $\mathrm{T}_{0}$ by extrapolating the $y$ intercept of the best-fit line.

44. Determine $\mathrm{T}_{\mathrm{C}}$ and $\mathrm{T}_{\mathrm{S}}$ using the following equations:

$$
\begin{gathered}
\mathrm{T}_{\text {plateau }}=\mathrm{T}_{\mathrm{C}}-\mathrm{T}_{\mathrm{S}}, \\
\mathrm{LI}_{0}=\mathrm{GF} \times\left(\mathrm{T}_{\mathrm{S}} / \mathrm{T}_{\mathrm{C}}\right) .
\end{gathered}
$$

Of note, more accurate calculations can be obtained using the spreadsheet developed by R. Nowakowski (Nowakowski et al. 1989), which allows drawing the best-fit line and calculates GF, $T_{C}$, and $T_{S}$ using a nonlinear regression method. With his kind authorization, the spreadsheet is included with this protocol as a supplemental file (see Supplemental File S1). Report your results for each retina at each time point as 
recommended and follow the included instructions. If publishing data gathered with this spreadsheet, Nowakowski et al. (1989) should be cited.

\section{Calculating $T_{G 2}$}

45. Plot the average percentage of EdU-positive cells among mitotic cells as a function of time (Fig. 1F).

46. Determine the time at which $50 \%$ of cells are labeled.

This corresponds to an estimation of $T_{G 2}$.

\section{Calculating $T_{M}$ and $T_{G 1}$}

47. Using the average percentage of $\mathrm{PH}^{+}$cells among total cells (MI) and the data gathered from EdU-cumulative labeling, calculate $\mathrm{T}_{\mathrm{M}}$ using the following equation:

48. Deduce $\mathrm{T}_{\mathrm{G} 1}$ using the following equation:

$$
\begin{gathered}
\mathrm{T}_{\mathrm{M}}=(\mathrm{MI} / \mathrm{GF}) \times \mathrm{T}_{\mathrm{C}}, \\
\mathrm{T}_{\mathrm{G} 1}=\mathrm{T}_{\mathrm{C}}-\left(\mathrm{T}_{\mathrm{S}}+\mathrm{T}_{\mathrm{G} 2}+\mathrm{T}_{\mathrm{M}}\right) .
\end{gathered}
$$

During development, neural stem/progenitor cells undergo extensive proliferation to give rise to a nervous system with a defined size and precise cellular diversity. It is now well established that cell cycle progression is tightly linked to cell fate decisions (Ohnuma and Harris 2003; Molina and Pituello 2016). In the developing retina, cell cycle speed was shown to determine whether early or late neuronal cell types are produced (Decembrini et al. 2006, 2009). This led to the idea of a cellular clock dependent on cell cycle progression that would measure the length of the last cell cycle rather than time (Pitto and Cremisi 2010). In addition, cell cycle lengthening is known to causally contribute to the switch from proliferative to neurogenic divisions in the developing brain (Calegari et al. 2005; Lange et al. 2009; Salomoni and Calegari 2010). It has been proposed that neurogenic factor action may depend on whether G1 length provides enough time to do it (Calegari and Huttner 2003). However, G1 is not the only phase subjected to length variation. G2-phase duration was found to be important for the proper control of neuronal production in the developing spinal cord (Peco et al. 2012; Molina and Pituello 2016). Finally, S-phase length was also highlighted as a key feature distinguishing self-expanding stem/progenitor cells (long $S$ ) from progenitors committed to a neurogenic lineage (short S) (Arai et al. 2011; Cabochette et al. 2015; Turrero García et al. 2016). The mechanisms underlying such modulations of cell cycle kinetics remain quite elusive. Indeed, apart from cell cycle regulators such as cyclin and cyclin-dependent kinases, only a few factors and signaling pathways have been shown to regulate the cell cycle progression of neural precursors (Martynoga et al. 2005; Locker et al. 2006; Komada et al. 2008; Uribe and Gross 2010; El Yakoubi et al. 2012; Peco et al. 2012; Cabochette et al. 2015). The ability to measure the length of the different phases of the cell cycle in vivo following gene perturbation is thus of utmost importance to further understanding this process. The $\mathrm{CMZ}$ represents a powerful system for such studies since its location and spatial organization allows one to (i) easily delineate it from the nonproliferative neural retina, and (ii) topologically distinguish stem versus progenitor cells (Perron et al. 1998) and thus specifically measure their respective cell cycle kinetics.

Although the percentage of labeled mitosis (PLM) and EdU cumulative labeling represent efficient tools for in vivo examination of cell cycle kinetics, it is fundamental to keep in mind their intrinsic 
limitations. First, and as mentioned in Box 1, EdU cumulative labeling and the PLM method presuppose that the studied proliferative population is in steady state. This criterion is barely fulfilled in developing tissues where total cell cycle duration and the lengths of the different phases vary dynamically throughout embryogenesis. It is, however, more or less met in the Xenopus CMZ, at least in late tadpole stages when retinal growth considerably slows down. A nonsteady state status is an important bias when calculating $T_{C}, T_{S}$, or $T_{G 2}$ because cells at the end of the labeling period might have a different cell cycle than those at its beginning. If significant variations in cell cycle speed are suspected during the labeling time period (for instance, based on the nonlinear aspect of the LI curve), an alternative method named "dual pulse labeling" can be considered. This technique is based on sequential administration of two different thymidine analogs such as EdU and IdU, CldU or BrdU (for the principle of this method, see Martynoga et al. 2005; for a protocol in Xenopus, see Auger et al. 2012). It allows estimating $T_{C}$ and $T_{S}$ using only one short time interval between injection of the two analogs (which diminishes bias from the nonsteady state of the considered population). A fundamental requirement for undertaking this experiment is to have antibodies able to discriminate between the two thymidine analogs in use.

A second and important drawback of PLM and EdU cumulative labeling (also true for dual pulse labeling) is that the calculated cell cycle parameters represent mean values which do not take into account the heterogeneity of the considered cell population. Live imaging of individual cells on neural tube slices from early chick embryos revealed striking heterogeneity, with $\mathrm{T}_{\mathrm{C}}$ values ranging from $\sim 9$ to $28 \mathrm{~h}$ (Wilcock et al. 2007). The average value was found to be similar to that calculated from fixed tissue. This perfectly illustrates how analysis of populations may hide a high inter-individual variability of cycling behaviors. Although this has not been addressed yet, it is very probable that CMZ progenitors show such cell cycle heterogeneity. The same might be true for retinal stem cells as well. In addition, rare dormant cells have recently been described at the extreme tip of the zebrafish CMZ (Tang et al. 2017), suggesting that the Xenopus retinal stem cell cohort might be composed of both "activated" proliferating cells and "resting" quiescent ones, as shown in neurogenic zones of the adult mammalian or zebrafish brain (Than-Trong and Bally-Cuif 2015; Chaker et al. 2016). Finally, our personal observations suggest that the dorsal and ventral parts of the CMZ do not proliferate at the same rate, indicating an additional regional heterogeneity in cell cycle progression. Live imaging in the zebrafish CMZ has recently been established (Wan et al. 2016). In association with genetic tools allowing for visualization of cell cycle phases (such as the Fucci technology, Sakaue-Sawano et al. 2008), this may help in the close future to assess cell cycle kinetics at the single cell level and to estimate variability among stem/progenitor cells.

$\mathrm{CaCl}_{2}(0.1 \mathrm{M})$

$11.1 \mathrm{~g} \mathrm{CaCl}_{2}$

Dissolve $11.1 \mathrm{~g} \mathrm{CaCl}_{2}$ in $1 \mathrm{~L} \mathrm{H}_{2} \mathrm{O}$. Autoclave and store in aliquots at $-20^{\circ} \mathrm{C}$ or $4^{\circ} \mathrm{C}$.

MBS Salts $(10 \times)$

$\mathrm{NaCl}(880 \mathrm{~mm})$

$\mathrm{KCl}(10 \mathrm{~mm})$

$\mathrm{MgSO}_{4}(10 \mathrm{~mm})$

HEPES (50 mM, pH 7.8)

Omit HEPES if MBS is to be used for oocyte maturation.

$\mathrm{NaHCO}_{3}(25 \mathrm{~mm})$

Adjust $\mathrm{pH}$ to 7.8 with $\mathrm{NaOH}$. Autoclave. Store at room temperature. 
Modified Barth's Saline (MBS)

$\mathrm{CaCl}_{2}(0.1 \mathrm{M})$

MBS salts $(10 \times)$

For a $1 \times$ solution of MBS, mix $100 \mathrm{~mL}$ of $10 \times$ MBS salts with $7 \mathrm{~mL}$ of $0.1 \mathrm{M} \mathrm{CaCl}_{2}$. Adjust the volume up to 1 liter with $\mathrm{H}_{2} \mathrm{O}$. Store at room temperature.

\section{ACKNOWLEDGMENTS}

The methods described here have been developed and optimized by several past members of the laboratory. We thank in particular Warif El Yakoubi, Caroline Borday, and Pauline Cabochette. We are very grateful to R. Nowakowski for providing the Excel spreadsheet and for his authorization to make it accessible to whomever requests to use it. M.P.'s laboratory is supported by grants from the FRM, Association Retina France and Fondation Valentin Haüy.

\section{REFERENCES}

Arai Y, Pulvers JN, Haffner C, Schilling B, Nüsslein I, Calegari F, Huttner WB. 2011. Neural stem and progenitor cells shorten S-phase on commitment to neuron production. Nat Commun 2: 154. doi:10.1038/ ncomms1155

Auger H, Thuret R, El Yakoubi W, Papalopulu N. 2012. A bromodeoxyuridine (BrdU) based protocol for characterizing proliferating progenitors in Xenopus embryos. In Xenopus protocols: post-genomic approaches (ed. Hoppler S, Vize PD), pp. 461-475. Humana Press, Totowa, NJ.

Cabochette P, Vega-Lopez G, Bitard J, Parain K, Chemouny R, Masson C, Borday C, Hedderich M, Henningfeld KA, Locker M, et al. 2015. Yap controls retinal stem cell DNA replication timing and genomic stability. Elife 4: e08488. doi:10.7554/eLife.08488

Calegari F, Huttner WB. 2003. An inhibition of cyclin-dependent kinases that lengthens, but does not arrest, neuroepithelial cell cycle induces premature neurogenesis. J Cell Sci 116: 4947-4955. doi:10.1242/jcs .00825

Calegari F, Haubensak W, Haffner C, Huttner WB. 2005. Selective lengthening of the cell cycle in the neurogenic subpopulation of neural progenitor cells during mouse brain development. J Neurosci 25: 6533-6538. doi:10.1523/JNEUROSCI.0778-05.2005

Chaker Z, Codega P, Doetsch F. 2016. A mosaic world: puzzles revealed by adult neural stem cell heterogeneity. Wiley Interdiscip Rev Dev Biol 5: 640-658. doi:10.1002/wdev.248

Decembrini S, Andreazzoli M, Vignali R, Barsacchi G, Cremisi F. 2006. Timing the generation of distinct retinal cells by homeobox proteins. PLoS Biol 4: e272. doi:10.1371/journal.pbio.0040272

Decembrini S, Bressan D, Vignali R, Pitto L, Mariotti S, Rainaldi G, Wang X, Evangelista M, Barsacchi G, Cremisi F. 2009. MicroRNAs couple cell fate and developmental timing in retina. Proc Natl Acad Sci 106: 21179-21184. doi:10.1073/pnas.0909167106

El Yakoubi W, Borday C, Hamdache J, Parain K, Tran HT, Vleminckx K, Perron M, Locker M. 2012. Hes4 controls proliferative properties of neural stem cells during retinal ontogenesis. Stem Cells 30: 2784-2795. doi:10.1002/stem.1231

Hendzel MJ, Wei Y, Mancini MA, Van Hooser A, Ranalli T, Brinkley BR, Bazett-Jones DP, Allis CD. 1997. Mitosis-specific phosphorylation of histone $\mathrm{H} 3$ initiates primarily within pericentromeric heterochromatin during G2 and spreads in an ordered fashion coincident with mitotic chromosome condensation. Chromosoma 106: 348-360. doi:10.1007/ s004120050256

Komada M, Saitsu H, Kinboshi M, Miura T, Shiota K, Ishibashi M. 2008. Hedgehog signaling is involved in development of the neocortex. Development 135: 2717-2727. doi:10.1242/dev.015891

Lange C, Huttner WB, Calegari F. 2009. Cdk4/cyclinD1 overexpression in neural stem cells shortens G1, delays neurogenesis, and promotes the generation and expansion of basal progenitors. Cell Stem Cell 5: 320-331. doi:10.1016/j.stem.2009.05.026

Locker M, Agathocleous M, Amato MA, Parain K, Harris WA, Perron M. 2006. Hedgehog signaling and the retina: insights into the mechanisms controlling the proliferative properties of neural precursors. Genes Dev 20: 3036-3048. doi:10.1101/gad.391106

Martynoga B, Morrison H, Price DJ, Mason JO. 2005. Foxg1 is required for specification of ventral telencephalon and region-specific regulation of dorsal telencephalic precursor proliferation and apoptosis. Dev Biol 283: 113-127. doi:10.1016/j.ydbio.2005.04.005

Molina A, Pituello F. 2016. Playing with the cell cycle to build the spinal cord. Dev Biol 432: 14-23. doi:10.1016/j.ydbio.2016.12 .022

Nowakowski RS, Lewin SB, Miller MW. 1989. Bromodeoxyuridine immunohistochemical determination of the lengths of the cell cycle and the DNA-synthetic phase for an anatomically defined population. J Neurocytol 18: 311-318. doi:10.1007/BF01190834

Ohnuma S, Harris W. 2003. Neurogenesis and the cell cycle. Neuron 40: 199-208. doi:10.1016/S0896-6273(03)00632-9

Peco E, Escude T, Agius E, Sabado V, Medevielle F, Ducommun B, Pituello F. 2012. The CDC25B phosphatase shortens the G2 phase of neural progenitors and promotes efficient neuron production. Development 139: 1095-1104. doi:10.1242/dev.068569

Perron M, Kanekar S, Vetter ML, Harris WA. 1998. The genetic sequence of retinal development in the ciliary margin of the Xenopus eye. Dev Biol 199: 185-200. doi:10.1006/dbio.1998.8939

Pitto L, Cremisi F. 2010. Timing neurogenesis by cell cycle? Cell Cycle 9: 434-435. doi:10.4161/cc.9.3.10762

Quastler H, Sherman FG. 1959. Cell population kinetics in the intestinal epithelium of the mouse. Exp Cell Res 17: 420-438. doi:10.1016/00144827(59)90063-1

Sakaue-Sawano A, Kurokawa H, Morimura T, Hanyu A, Hama H, Osawa H, Kashiwagi S, Fukami K, Miyata T, Miyoshi H, et al. 2008. Visualizing spatiotemporal dynamics of multicellular cell-cycle progression. Cell 132: 487-498. doi:10.1016/j.cell.2007.12.033

Salomoni P, Calegari F. 2010. Cell cycle control of mammalian neural stem cells: putting a speed limit on G1. Trends Cell Biol 20: 233-243. doi:10 $.1016 / j . t c b .2010 .01 .006$

Tang X, Gao J, Jia X, Zhao W, Zhang Y, Pan W, He J. 2017. Bipotent progenitors as embryonic origin of retinal stem cells. J Cell Biol 216: 1833-1847. doi:10.1083/jcb.201611057

Than-Trong E, Bally-Cuif L. 2015. Radial glia and neural progenitors in the adult zebrafish central nervous system. Glia 63: 1406-1428. doi:10 $.1002 /$ glia.22856

Turrero García M, Chang Y, Arai Y, Huttner WB. 2016. S-phase duration is the main target of cell cycle regulation in neural progenitors of devel- 
oping ferret neocortex. J Comp Neurol 524: 456-470. doi:10.1002/cne .23801

Uribe RA, Gross JM. 2010. Id2a influences neuron and glia formation in the zebrafish retina by modulating retinoblast cell cycle kinetics. Development 137: 3763-3774. doi:10.1242/dev.050484

Wan Y, Almeida AD, Rulands S, Chalour N, Muresan L, Wu Y, Simons BD, He J, Harris W. 2016. The ciliary marginal zone of the zebrafish retina:
In Vivo Assessment of Cell Cycle Kinetics in the Retina

clonal and time-lapse analysis of a continuously growing tissue. Development 143: 1099-1107. doi:10.1242/dev.133314

Wilcock AC, Swedlow JR, Storey KG. 2007. Mitotic spindle orientation distinguishes stem cell and terminal modes of neuron production in the early spinal cord. Development 134: 1943-1954. doi:10.1242/dev .002519 


\section{In Vivo Assessment of Neural Precursor Cell Cycle Kinetics in the Amphibian Retina}

Morgane Locker and Muriel Perron

Cold Spring Harb Protoc; doi: 10.1101/pdb.prot105536 originally published online May 30, 2019

\begin{tabular}{|c|c|}
\hline $\begin{array}{r}\text { Email Alerting } \\
\text { Service }\end{array}$ & Receive free email alerts when new articles cite this article - click here. \\
\hline $\begin{array}{l}\text { Subject } \\
\text { Categories }\end{array}$ & $\begin{array}{l}\text { Browse articles on similar topics from Cold Spring Harbor Protocols. } \\
\text { Cell Biology, general (1382 articles) } \\
\text { Cell Imaging (525 articles) } \\
\text { Fluorescence ( } 517 \text { articles) } \\
\text { Fluorescence, general ( } 341 \text { articles) } \\
\text { Image Analysis (124 articles) } \\
\text { Imaging Development (255 articles) } \\
\text { Imaging for Neuroscience (342 articles) } \\
\text { Xenopus ( } 210 \text { articles) }\end{array}$ \\
\hline
\end{tabular}

